\title{
Shane and the Language of Men
}

\author{
https://doi.org/10.1515/arcadia-2018-0005
}

\begin{abstract}
Jane Tompkins has argued that a deeply conflicted relationship exists between men and language in the Western. Deploying too much language emasculates Western heroes, men who privilege action over talk. For support, Tompkins turns to a number of moments in Shane, the 1953 film adaptation of the 1949 novel of the same title by Jack Schaefer. Tompkins argues that the film constructs a model of masculinity that wholly rejects language, a move that is destructive and exploitative to self and others. However, a close reexamination of the novel reveals a model of masculinity that is more positive and flexible towards language and gender than Tompkins's views on the Western suggest. A close rereading of the novel shows that men in Westerns do not always use talk and silence to subjugate women and others, and that the valuing of language over action does not always end in violence or exploitation. Furthermore, the film adaptation of the novel will be examined, a work that occupies a more cherished place in American culture than the novel, a situation that is the reverse of traditional cultural hierarchies in which the literary source material is privileged over the film adaptation. Ultimately, the novel and film are engaging in different ways, yet Schaefer's novel, rather than being relegated to middle school literature classrooms, rewards serious critical and scholarly attention, particularly in the context of the film adaptation and critical discourse on the representation of masculinity in the Western.
\end{abstract}

Keywords: masculine studies, Jack Schaefer, Shane, literary studies, adaptation

\section{Introduction}

Though nearly seventy years old, the Western Shane continues to occupy a visible and viable position in American culture. Jack Schaefer's novel, which deals with a young boy coming of age on the frontier and his relationship with a mysterious stranger that defends the community against a corrupt cattle rancher, has been translated into over thirty languages, has appeared in over seventy editions, and

Corresponding author: Jesse Gerlach Ulmer, Virginia Commonwealth University in Qatar, P. 0. Box 8095, Doha, State of Qatar, email: ulmerjg@vcu.edu

2 Open Access. () Jesse Gerlach Ulmer, published by De Gruyter. (c) BY This work is licensed under the Creative Commons Attribution 4.0 License. The publication of this article was funded by the Qatar National Library. 
today sells around 120,000 copies annually (Marsden 340). The American Film Institute (AFI) considers the 1953 film adaptation of the novel, directed by George Stevens, to be one of the top five most important American Westerns of all time, sharing company with such esteemed works as John Ford's The Searchers (1956) and Fred Zinnemann's High Noon (1952). Shane has even managed to transcend national borders to form part of the global imagination of the American West - a special edition of Shane was produced to help Japanese speakers learn English, and the United States Information Agency published an edition as an approved export of American culture (Marsden 340).

Despite this broad popular appeal, however, some critics have been less than impressed with Shane. As enumerated by Matthew Costello in “"I Didn't Expect To Find Any Fences Around Here': Cultural Ambiguity and Containment in Shane,” Shane has been characterized by a number of critics as a conventional, paradigmatic, "classic" example of the genre, one that perpetuates ideological orthodoxy and reinforces the social status quo (269). While this line of criticism applies to the novel, more often than not, it is, implicitly or explicitly, directed towards the film adaptation. Jane Tompkins argues in West of Everything: The Inner Life of Westerns, for instance, that the film version of Shane is symptomatic of the genre's general tendency to perpetuate rigid gender norms by emphasizing Shane's masculine rejection of language. Tompkins argues that Shane offers a prime example of the deeply conflicted, structural relationship that exists between language and men. "For the really strong man, language is a snare; it blunts his purpose and diminishes his strength” (51). In Tompkins's view, language emasculates Western heroes, mythic men who privilege action over dialogue, doing over talking. For evidence, Tompkins turns to a moment in the film version of Shane:

\footnotetext{
When Bob asks Shane if he knows how to use a rifle, Shane answers, and we can barely hear him, "Little bit." The understatement and the clipping off of the indefinite article are typical of the minimalist language Western heroes speak, a desperate shorthand, comic, really, in its attempt to communicate without using words. (51)
}

Tompkins characterizes Shane's use of language as “desperate,” even “comic," adding that characters who regularly resort to the use of language in Westerns are usually treated with "contempt." "Braggarts," for instance, "are dead men as soon as they appear" (51). Again, Shane is cited: "When 'Stonewall' Tory [...] brags that he can face the Riker gang any day, you know he's going to get shot; it's Shane, the man who clips out words between clenched teeth, who will take out the hired gunman.” (51) For Tompkins, the cinematic version of Shane constructs a model of masculinity that renounces language in ways that are exploitative and destructive of self and others. Taciturn Western heroes such as Shane are, at bottom, textbook examples of psychologically and socially dysfunctional American men. 
While Tompkins's and other criticisms of the film version of Shane are valid in a number of respects, the source text - Jack Schaefer's 1949 novel - presents something different. In the novel, the characterization of the lone gunman from the east is more problematic as it pertains to the relationship between gender and language. In contrast to the notion that Shane denotes a classic Western hero, a textbook example of conventional "cowboy masculinity," I argue in this article that a careful reexamination of Shane's characterization in the novel suggests a rather unusual portrait of the cowboy-hero, one that blends masculinization and feminization. In the novel, Shane is shown to practice a more flexible, open discourse, one that can move easily between masculine and feminine topics. In addition, the novel explores the perils and promises of nonverbal communication, particularly in the famous stump-pulling sequence. Reconsidering curious moments within particular Westerns like the novel version of Shane can reveal surprising and interesting generic variations that complicate oversimplified, dogmatic, binary views of the relationship between gender and language.

\section{Critical Framework: Masculinity Studies}

My critical analysis is guided by many of the trajectories and projects of contemporary research on masculine subjectivity. A highly interdisciplinary endeavor that questions the construction of masculinity across time and space, current research in the field approaches masculinity not as a normative referent but as a problematic, polymorphous, gender construct. Some of the specific goals of studying masculinity (or masculinities, rather) include a critique of the ways masculinity is socially, politically, economically, and culturally situated and the interrogation of what it means to be a man at a particular historical moment. Though the field of masculine studies owes much to the social sciences, it is also frequently studied in the humanities, not through a quantitative epistemology but through a qualitative approach that positions masculinity as an issue of representation, foregrounding language and signs as the primary object of analysis. This is the approach I adopt in this essay. Another goal of contemporary research on masculinity - one that I wholly endorse in this article - concerns the re-search for more complicated and positive models of masculinity that operate in nonhegemonic ways, or as Todd W. Reeser puts it in Masculinities in Theory,

moments in which men break or attempt to break their own hold over power and the ways in which purely critical views of masculinity can be supplemented by more positive ones. If masculinity's hegemonic operations can be hidden, they can also be subverted, male power can be destabilized, and experiences outside hegemony can be created. (134) 


\section{Shane: Background Information}

Born November 19, 1907 in Cleveland, Ohio, Jack Schaefer began writing the story that would become Shane in 1944; he wrote mostly at night, after finishing his day job as acting editor of the Norfolk Virginia Pilot. Interestingly, prior to the publication of Shane, Schaefer had never been west of Ohio, which makes Shane a truly imagined version of the Western frontier. The story that would eventually become the novel Shane was first published in 1946 as "Rider From Nowhere" in a threepart serial in the July, September, and October issues of Argosy magazine. In 1949, the story was bought by Houghton Mifflin, retitled Shane, and published as a novel in a hardbound edition (Marsden 339-340). Initially published for a mature audience, the novel was subsequently revised and reprinted in 1954 for younger readers (Worden 143). Inspired by the historical events of the 1892 Johnson County War in Wyoming, which pitted settlers against cattle ranchers, Schaefer's novel, set in 1889, is narrated by young Bob Starrett, the son of a determined settler, Joe Starrett, and his wife, Marian. One day, an enigmatic stranger named Shane rides into the Starrett homestead, befriends the family, and stays on to work as a farmhand. Meanwhile, a local cattle rancher named Luke Fletcher wants the land the homesteaders are using to expand his herd. Fletcher hires cowhands and gunslingers to harass the homesteaders, including the Starretts. It is apparent when Shane first appears in the valley that he is a gunslinger himself, though one that is trying hard to leave his troubled past behind. The conflict with Fletcher escalates to the point where Shane must confront and defeat Fletcher and his men in a violent showdown, after which Shane departs the valley. In 1953, the novel was adapted to film by Paramount Pictures, directed by George Stevens and written by A. B. Guthrie, Jr. Starring Alan Ladd as Shane, the film was a popular and critical success, receiving five Academy Award nominations, including Best Picture.

\section{The Construction of Shane's Masculinity: Film vs. Novel}

One of the most striking differences between the novel and the film is the way in which Shane is introduced as a character, particularly in the way masculinity is performed. Comparing the beginning of the film and novel helps highlight the different ways in which Shane's masculinity is constructed. Both the novel and film open with the entrance of Shane into the valley and riding up to the Starrett homestead. In the film, Shane is visualized through the mise-en-scène as an 
instance of the "natural man." He rides into view from off camera, across midscreen, down into a lush green valley encompassed by the majestic Grand Tetons. Shane is clad from head to toe in buckskin leather, resembling Daniel Boone. As Daniel Wordern points out in Masculine Style: The American West and Literary Modernism, Shane appears as a "kind of Natty Bumppo figure" who symbolizes "mythological Western primitivism" (147). In the novel, Shane is presented in ways that depart from the notion of a hyper-masculine, primitive frontiersman. As Young Bob Starrett observes Shane approach the family homestead, what initially strikes him is the peculiar way Shane is dressed:

As he came near, what impressed me first was his clothes. He wore dark trousers of some serge material tucked into tall boots and held at the waist by a wide belt, both of a soft black leather tooled in intricate design. A coat of the same dark material as the trousers was neatly folded and strapped to his saddle-roll. His shirt was fine-spun linen, rich brown in color. The handkerchief knotted loosely around his throat was black silk. His hat was not the familiar Stetson, not the familiar gray or muddy tan. It was a plain black, soft in texture, unlike any hat I had ever seen, with a creased crown and a wide curling brim swept down in front to shield the face. (62)

Shane is presented as an urbane eastern dandy who eschews the iconic Stetson hat - an accessory inextricably linked to archetypal Western cowboys. Bob remarks that he is "fascinated" by Shane for "[n]one of the men I knew were proud like that about their appearance” (67). As Daniel Worden observes, while young Bob Starrett is a child in the narrative, he is telling the story retrospectively as an adult, one who "has had a chance to live out his boyhood and grow straight inside as a man should" (Schaefer 273). This suggests that Bob veritably speaks from “the secure vantage point of a normative ‘straight' man” (145). Recognizing Bob's normative masculine perspective underlines even more emphatically Shane's departure from mainstream gender codes of dress and behavior. Shane is fashionable, a fact Bob's mother, Marian, infers though the many questions she poses to Shane "about what the women are wearing back in civilization. You know, hats and such" (79). To Marian, Shane signifies "the kind of man would notice them" (79). Marian begs Shane "to describe the ladies he had seen in Cheyenne and other towns where the new styles might be” (81). Rather than evade Marian's inquiries, questions that considered from a more normative perspective would compromise Shane's masculine cachet, young Bob observes that Shane "sat there, easy and friendly, telling her how they were wearing wide floppy-brimmed bonnets with lots of flowers in front on top and slits in the brims for scarves to come through and be tied in bows under their chins" (81). Shane fluently speaks Marian's feminine discourse. As Bob observes, "Shane was not bothered at all” by this kind of talk (81). This scene underscores the fact that Shane is secure and confident about his masculinity, perceiving no real threat to his manhood by 
sharing his knowledge of urban fashion trends with Marian in front of the Starrett men.

Unlike Marian, the Starrett men detect something deviant in Shane's behavior. Bob remarks that "[t]alk like that seemed foolish to me to be coming from a grown man" (81). The Starrett men are clearly circumscribed by a more limited conception of male behavior. Joe warns Shane not to give Marian "fancy notions of new hats so she'll be sending off to the mail-order house and throwing my money away on silly frippery" (80). What is cherished within Marian's feminine value-system is roundly delegitimized by Joe's remark. Joe finds the conversation between Marian and Shane boring and silly, preferring to talk about crops and steers, a more narrowly 'male' topic of conversation. Shane is equally comfortable speaking language identified as male, however, and readily engages Joe on the finer points of farming strategy. Considering this scene as a whole, Shane sponsors a mode of discourse that is flexible and situational, an unusual male character trait in a genre ostensibly committed to perpetuating orthodox notions of what it means to be a man. Towards the end of the scene, Shane's versatile discourse functions as a social bonding agent that unites the Starrett family and generates one of the most poignant lines of the novel: "And the rain outside was a far distance away and meaningless because the friendly feeling in our kitchen was enough to warm all our world." (81) A large part of what animates this "friendly feeling," a sense of familial connectedness and harmony, is realized through Shane's ability to be, in a sense, everything to everyone (though not, obviously, to Fletcher and his gang), an acuity actuated through the very element - language - that Tompkins claims is lacking in characters like Shane. Shane speaks a discourse that is multi-directional, one that oscillates comfortably between both gender poles. Shane can speak across strictly gender-coded categories of behavior, giving him a flexibility that marks him as rare and special. Moreover, a prominent theme running through much of Schaefer's work is young boys coming of age, a ritual that involves choosing from among a number of adults different models of behavior to emulate (Ersiman). To young Bob, Shane represents one of these potential models, and one of his key heroic traits is the way in which he models a version of discourse that can just as easily speak male as well as female language.

Shane does not reject language so much as he is careful in choosing his words and when and to whom he speaks them, suggesting a keen awareness of and respect for the power of language and social context. In their first meeting, Shane observes that Bob watched him approach the Starrett homestead "for quite a spell" (69). Bob feels nervous in the presence of Shane, stammering in the affirmative, to which Shane responds, "Right [...] I like that. A man who watches what's going on around him will make his mark" (69). Bob reflects that "for all his 
dark appearance and lean, hard look, this Shane knew what would please a boy. The glow of it held me as he took care of his horse [...].” (69) Shane's compliment boosts Bob's self-confidence, ameliorating his maturation process. Shane intuitively understands that the young and impressionable Bob already looks up to him as a male role model. Bob never openly articulates this idea to Shane, but the point is that Bob does not have to, for it is the nature of Shane's persona to implicitly recognize the unspoken dynamics of the situation and respond in ways that are socially and psychologically productive. Shane is presented as a sharp and sensitive observer who considers carefully his rhetorical context before verbalizing his thoughts. He is deeply attuned to the needs and expectations of others and often uses language to fulfill them. The first time Shane speaks in the novel, despite the "sudden chill” Bob registers in response to Shane's scannerlike eye movements, Bob states that "his voice was gentle and he spoke like a man schooled to patience" (65). Shane's first use of language in the novel, his character establishing utterance, as it were, is "gentle" and "patient," formulated as a polite request: "I'd appreciate a chance at the pump for myself and the horse." (65) Shane's approach to oral expression is ultimately more mannered or genteel than it is anti- or re(o)pressive.

\section{Postwar Westerns: a Romance of Competence}

How are we to understand what appears to be a significant departure in a genre that otherwise seems deeply committed to perpetuating rigid representations of masculinity? What conditions make such an unusual characterization possible? In the novel, as Shane remounts his horse to leave the Starrett homestead, Bob remarks that "[e]verything about him showed the effects of long use and hard use, but showed too the strength of quality and competence" (67). "Quality" and "competence" are two key words here, suggesting a model of masculinity based more on marshaling whatever resources will contribute to realizing success in any endeavor than performing a heavily prescribed version of gender. In "The Romance of Competence: Rethinking Masculinity in the Western,” Wendy Chapman Peek argues that "the Western is not primarily a romance of masculinity but a romance of competence, and that the man who demonstrates a range of abilities broad enough to address any perilous situation gets to be the hero" (208-209). Whether the resources Western male heroes exploit are identified as feminine or masculine matters less than the extent to which the hero succeeds in achieving goals. Furthermore, Peek comments that "[h]ow competence is defined [...], which abilities are shown to succeed, varies from period to period” (209). For example, "in postwar Westerns of the 1940s and 1950s, competence involves the mastery of 
a variety of skills, some marked as masculine, others as feminine” (209). Schaefer began composing Shane in 1945, and it was published in 1949, two facts that plant the novel squarely in the postwar period in which an interest in representing allaround competency was a dominant strategy for creating male Western heroes.

Peek bases her findings on a close analysis of several postwar Western films, and though Shane is not explicitly discussed, her observations about masculine gender codes in films like Ford's Fort Apache (1948) apply equally to the novel version of Shane. Peek claims that certain postwar Western movies "offer evidence of a masculinity that does not fight femininity but incorporates it," ultimately demonstrating that

\footnotetext{
[t]he achievement of competence demands that the hero use a variety of behaviors, including those 'coded' as feminine, to realize his goals and that he engage in these behaviors without being irrevocably marked by that effeminacy. This Western does not mourn the feminization of the hero; rather, it celebrates his versatility and the special 'flexibility' that it takes to play the woman. (209)
}

These insights into the gender dynamics of postwar Westerns help contextualize Shane's ability in the novel to activate language in ways tagged as feminine. Although Shane is identified as effeminate by every member of the Starrett family, this identification is not, as Peek qualifies, "irrevocable" (209). Shane's ability to speak on equal terms with Bob, Joe, and Marian is presented as supremely positive, generating social warmth and cohesion. Shane represents an intermediary figure between Joe and Marian, a middle state situated between two polarized modes of gender. Joe wants to talk livestock and agriculture; Marian wants to talk style and dress. Shane shuttles between the two while Bob, along with the reader, observes the shifting dynamics. Joe and Marian compete for Shane's attention. Joe speaks to Shane about something masculine, Marian interrupts to speak to Shane about something feminine; this pattern recurs. In the midst of this tug of war, Shane displays a remarkable ability to reconcile both modes within himself, occupying a stable middle ground between two typically opposed modes of discourse. Shane incorporates both masculine and feminine elements into his identity without generating any apparent paradox or conflict.

The relationship between language and character in other figures in the novel adheres more to normative expectations. Young Bob's approach to discourse tends to mirror that of his father, Joe, who expresses himself in ways that avoid domestic or feminine topics, preferring instead to talk crops and cattle. Marian's talk is conditioned by her traditional domestic role, signified by her strong links with eastern civilization, fashion, baking, family, love, home, and stability. Fletcher, the novel's central antagonist and character foil to Shane, is a shadowy, distant figure mostly absent from the principal settings of the narrative, but when 
he eventually appears, he verbally expresses himself in terms of business, money, and power, the archetypal American white male discourse.

Shane is not the only cowboy hero in the history of the genre to be endowed with moments of rhetorical skill that problematize gender norms. Oral prowess represents a defining trait of a number of Western male heroes such as Doc Holliday in My Darling Clementine (1946), with his moving recitation of Shakespeare. In fact, this trait reaches all the way back to Owen Wister's The Virginian, a work commonly viewed as a genesis text of the genre. Lee Clark Mitchell expounds on the Virginian's skillful use of language, observing that film adaptations tend to de-emphasize this trope, creating a more tight-lipped, "yup and nope" Virginian, like the one played by Gary Cooper (66). The representation of these three characters - The Virginian in Wister's novel, Doc Holliday in $M y$ Darling Clementine, and Shane in Schaefer's novel - connote an interesting strain of heroic male winding through the Western genre, one that disrupts over-simplified views of men and language.

Lee Clark Mitchell's observation that film adaptations of The Virginian tend to de-emphasize the Virginian's way with words is instructive, for something very similar appears to be happening in the case of Shane. This could be a product of the shift in medium, for novels rely heavily on words while film is more of a visual medium. Regardless, the shift in Shane's character from urban dandy (novel) to natural man (film) is attended by a shift in language (talkative to tight-lipped). Comparing the dinner scene with Shane and the Starrett family in the novel to the same scene in the film, Joe does nearly all the talking, Marian speaks very little, and Shane, not at all. When Marian finally manages to say something, she tells her son, renamed Joey, to be quiet, "the men want to talk" (Stevens). One could argue that this difference confirms that Tompkins's arguments are ultimately accurate in the context of the film. However, Tompkins makes it clear that her claims about gender and language apply to all Westerns: "the genre is in revolt against a Victorian culture where the ability to manipulate language confers power, the Western equates power with 'not-language.' And not language it equates with being male" (55). The "it" in these statements implicates the entire genre, inferring a totalizing view, a master critical narrative. The notion animating Tompkins's tendency to over-generalize springs from the common view that popular genres like the Western are formulaic, predictable. Structuralism as applied to genre theory regularly infers that most iterations of a genre are unified by a common vocabulary, a universal grammar. While this method or approach is productive and, to some extent, necessary no matter how imperfect, moments in the novel version of Shane suggest that such a homogenizing view is, ultimately, indefensible. Genres are more diverse and offer more surprising variations at times than is often admitted or at least qualified. 
I am not suggesting that Shane the novel is inherently superior to Shane the film, or that the quality of the film should be evaluated by the degree to which it is faithful to the novel, commonly referred to in adaptation studies as fidelity criticism. In fact, one of the remarkable aspects about Shane from a literature to film standpoint is that the film tends to occupy a more esteemed and visible position in American culture, as the AFI ranking noted in the introduction suggests. Indeed, it is my experience that more people have seen the film version of Shane than have read the novel (in fact, it is rather rare to come across someone who has read the novel, even among devoted fans of the genre). What I am suggesting is that a close reexamination of the novel, which is today too often overlooked or has been forgotten in the long shadow cast by the success of the film, rewards close re-reading, offering curious and surprising moments in the context of contemporary critical discourse on the Western, adding to the list of male protagonists in the Western who, in one way or another, use language in more flexible, dynamic ways.

\section{Nonverbal Communication in the Stump-Pulling Chapter}

This dynamic goes beyond verbal forms of language and explores alternative forms of character expression and representation like nonverbal communication. I do not disagree with the observation that Westerns tend to value action over words. Much of Tompkins's theory about language in the Western has to do with the epistemology of language, that is, its truth-value, its capacity to accurately describe or capture reality. In the Western, Tompkins argues, "language is false or at best ineffectual; only actions are real" and "language constitutes an inferior kind of reality, and the farther one stays away from it the better" (51). I do not fully subscribe to what syllogistically follows, however, which is that it is always socially and psychologically destructive. Tompkins asserts that the position of language "is deliberately proven wrong - massively, totally, and unequivocally with pounding hooves, thundering guns, blood and death" (55). Perhaps it is ultimately more accurate and productive to say that the restrained or careful use of language by male Western heroes is actually directed towards a specific kind: the verbal. Perhaps the genre wishes to explore a form of language made not of words, but of the nonverbal, something wholly underappreciated by critics and that, furthermore, might represent the preeminent communication style in the Western. Though I lack space in this essay to properly validate and elaborate this claim, I would like to at least start the conversation by looking at a few important 
moments in Shane that reflect on the power and pitfalls of nonverbal communication among men in the Western.

While I have suggested that Shane is more talkative than conventional cowboys, what I want to stress is that his use of language is more flexible than the standard type. It is not about how much he talks, but the way he talks, which is to say, his discourse. Shane's remarkable ability to be 'everything to everyone' means that at times situations might arise that call for not using language at all, or rather, using a different form of language altogether, such as nonverbal forms of communication. Nonverbal language is a deeply important and complex form of communication, and plays a critical role in our everyday interactions. According to Vijai N. Giri, nonverbal communication includes "personal feelings, emotions, attitudes, and thoughts through body movements - gestures, postures, facial expressions, walking styles, positions, and distance - either consciously or involuntarily, more often subconsciously, and accompanied or unaccompanied by the spoken language," thus denoting "the way people unconsciously telegraph their private thoughts and emotions through body movements" (692). Theoretically, there are thought to be seven modes or analytical categories of nonverbal communication: proxemics (personal space/proximity), haptics (touch), oculesics (eye contact), chronemics (time/duration), kinesics (body language, physical cues), physical environment-appearance (interior design, lighting, noise, etc.), and paralanguage (the vocal element of speech) (693). The establishment of trust between Joe and Shane in the novel is realized through many of these modes of nonverbal communication, often used in combination with one another and influenced by the context of the situation. After Shane refreshes himself and his horse and remounts to leave the valley, Joe tells Shane not to be in such a hurry. Bob observes that "[a]t the first sound of father's voice, the man and the horse, like a single being, had wheeled to face us, the man's eyes boring at father, bright and deep in the shadow of the hat's brim" (68). This is a situation pregnant with violence, a moment of distrust signified by Shane's careful and constant scanning of the environment for potential threats. The two men stare intently at one another, "measuring each other in an unspoken fraternity of adult knowledge" and then, suddenly, Bob states that "warm sunlight was flooding over us" (68). No violence erupts, and the tension dissolves through a kind of half conscious, half subconscious exchange of nonverbal cues. The moment is bathed in warm sunlight, a recurring image throughout the novel that denotes social harmony. Nonverbal forms of language activate in a moment urgent with violence to pacify and harmonize, to cement a close and enduring friendship. There is something rather mystical about this scene, as if there exists a kind of supernatural bond between Shane and Joe. Nevertheless, their communication is expressed, and interpersonal alignment is established, through nonverbal means. Body language 
also plays a critical role in the famous stump-pulling sequence - a scene given greater depth in the novel than the film - where it functions as a constructive way for Shane to rehabilitate his violent narrative and to enact a male-bonding ritual with Joe, one that is heavily laden with homoerotic overtones.

The importance of the stump-pulling chapter to the meaning of the novel is reinforced by the fact the chapter as a whole was added to the text - the only significant addition, in fact - when Schaefer revised the story from the original three-part magazine serial published in Argosy into a novel in 1948 (Marsden 341). Interestingly, the film and the novel differ in how they construe this sequence. The pretext in the film for Shane to work at the stump is presented as a straightforward means to repay the Starrett family for their hospitality. In the novel, the reasoning for Shane's initiative to remove the stump is more complex. In the previous scene, a travelling salesman named Ledyard visits the homestead to offer Joe a cultivator. Ledyard quotes a price of a hundred and ten dollars; Shane interrupts the negotiations to point out that he noticed a similar cultivator in Cheyenne selling for sixty dollars. Ledyard tells Joe to ignore Shane, that he is "just a stray wandering through, probably chased out of some town and hunting cover" (87). Ledyard is deeply bothered by Shane's attempts to cheat him out of a large profit. Finally, "the climbing anger in Ledyard broke free," yelling, "Starrett! Are you going to stand there and let that - that tramp nobody knows about call me a liar? Are you going to take his word over mine? Look at him! Look at his clothes! He's just a cheap, tinhorn -” (88). At this point, Shane suddenly turns dark and threatening:

\footnotetext{
Ledyard stopped, choking on whatever it was he had meant to say. He fell back a step with a sudden fear showing on his face. I knew why even as I turned to see Shane. That same chill I had felt the day before, intangible and terrifying, was in the air again. Shane was no longer leaning against the porch post. He was standing erect, his hands clenched at his sides, his eyes boring at Ledyard, his whole body alert and live in the leaping instant. You felt without knowing how that each teetering second could bring a burst of indescribable deadliness. Then the tension passed, fading in the empty silence. Shane's eyes lost their sharp focus on Ledyard and it seemed to me that reflected in them was some pain deep within him. (88)
}

Silence signifies Shane turning inward to face a painful past of violence and trauma. Silence, not talk, in this scene enables a non-violent outcome, a moment signaling deep inner awareness of the past and an attempt to mediate destructive patterns of behavior in the present. Joe defends Shane, saying, "I'll take his word on anything he wants to say any day of God's whole year." (89) After Ledyard departs, Bob and Joe "looked around for Shane and he was not in sight" (90). Moments later they spot Shane "coming out of the barn" and "carrying an axe" (90). They "stare after him" until they hear "the clear ringing sound of steel biting into wood" (90). As Shane chops away at the stump, Joe says there is no reason 
for Shane to do anything in exchange for their hospitality. "A man has to pay his debts," Shane responds (91). The apparent meaning of Shane's statement is that the "debt" he is paying off is one to the Starrett family, which is how the film interprets the metaphor. In the novel, Young Bob also interprets the meaning of Shane's actions in this way, saying, "You don't owe us anything. [...] Lots of times we have folks in for meals and -" (91). But Bob is interrupted by Joe, who says, “No, Bob. He doesn't mean meals" (91). On one level, the "debts" Shane is "paying off" are in exchange for Joe's defense of Shane against Ledyard. On another level, however, the balance has to do with much deeper "debts" accrued in a violent, traumatic past. Gordon L. Iseminger in "Corral Posts and Tree Stumps: Symbolism in Jack Schaefer's Shane" observes that "the very stubbornness of the stump's roots, their resistance to fire and axe, symbolizes the difficulty Shane faces when trying to cut himself off from his past" (258). The stump as a symbol of a repressed traumatic past is metaphorically reinforced by Bob's description: "the huge old roots humped out in every direction [...] pushing out and twisting down into the ground like they would hold there to eternity and past" (83). When Joe joins Shane in working on the stump, Bob remarks that "their eyes met over the top of the stump and held and neither one of them said a word" (93). This moment of silence and joint labor/action - interestingly, a form of nonverbal communication not explicitly addressed by the seven modes outlined above - unifies the efforts of both men, less a rejection of language than an embrace of another form, the nonverbal, here expressed through rigorous physical labor. Bob characterizes the work of Shane and Joe as a metaphorical dialogue: "they swung up their axes and both of them said plenty to that old stump" (93). The clearing of the stump could be seen as symbolic of the taming of the Western frontier by the indefatigable and triumphant will of white American pioneers and homesteaders. But for Shane, clearing the stump is a form of sublimation, a redirection of violent, socially unproductive energy into a more positive expression of masculine behavior.

A serious social and gender equality problem arises in this sequence of nonverbal and nonviolent male bonding, however - it excludes Marian, relegating her to a traditional female role. While the two men chop away at the stump, Bob notes that a beautifully dressed Marian appears:

She was the freshest, prettiest thing I had ever seen. She had taken her hat and stripped the old ribbon from it and fixed it as Shane had told her. Some of the flowers by the house were in a small bouquet in front. She had cut slits in the brim and the sash from her best dress came around the crown and through the slits and was tied in a perky bow under her chin. She was stepping along daintily, mighty proud of herself. (95) 
Although clearly dressed to draw attention, Bob observes that "[t]hose two choppers were so busy and intent that even if they were aware she was there they did not really notice her" (95). The men, "busy and intent” on their work, refuse to pause and admire Marian's appearance. Finally, Marian interrupts their work, saying, "Well, [...] aren't you going to look at me?” The men pause and Marian asks Shane: "Have I got it right? [...] Is this the way they do it?" (95) Shane responds, "Yes, ma'am. [...] About like that. Only their brims are wider." (95) Shane says nothing more and goes back to work. Increasingly frustrated, Marian turns to Joe: "Joe Starrett, [...] aren't you at least going to tell me whether you like me in this hat?" to which Joe responds, "Lookahere, Marian, [...] you know damned well that whether you have a hat on or whether you don't have a hat on, you're the nicest thing to me that ever happened on God's green earth. Now stop bothering us. Can't you see we're busy?" (96). Marian is rejected, ignored, by both men, a move that places her in a subordinate position, consigning her to a conventional role. When the two men come in for dinner, an uncomfortable silence reigns. Though Marian talks politely, Shane and Joe "listened absently to her talk, chiming in when she asked them direct questions, but otherwise keeping quiet. Their minds were on that old stump and whatever it was that old stump had come to mean to them and they were in a hurry to get at it again" (97). In the previous dinner scene, Marian is equalized with Joe and Shane; in this scene, she is devalued, regarded as an unwanted distraction from the more serious business of removing the stump. The cost of nonverbal male bonding in this sequence appears to be the devaluing of women.

Though the representation of nonverbal language negates women, it is supremely positive for men, enabling a nonviolent, constructive form of intercommunication and cooperation. For Tompkins, nonverbal language in the Western usually ends in physical violence inflicted upon others. Here, however, nonverbal dialogue builds an intimate, profound bond between Joe and Shane. As Joe and Shane finally remove the stump, they embrace silence as a way to communicate: "They both looked up and their eyes met and held as they had so long ago in the morning hours." (107) Bob remarks that "the silence should have been complete" but that "it was not because someone was shouting, a high-pitched, wordless shout. I realized the voice was mine and I closed my mouth.” (107) Bob's "wordless shout" signifies an attempt to share in the two men's primal victory over the stump, one that is "wordless" but no less powerful for being so. Bob immediately shuts his mouth, realizing that

[t]he silence was clean and wholesome, and this was one of the things you could never forget whatever time might do to you in the furrowing of the years, an old stump on its side 
with root ends making a strange pattern against the glow of the sun sinking behind the far mountains and two men looking over it into each other's eyes. (108)

Bob interprets the silence as "clean and wholesome," generating a strangely grotesque image of the upended stump roots silhouetted against the orange glow of the setting sun. Silence generates a moment of male intimacy that is one of the deepest and most profound to be shared between two males in the novel, perhaps even in the genre as a whole. The coordinated efforts of the two men nearly merge, a unification that Bob feels is appropriate: "I thought they should join the hands so close on the bole of the stump. I thought they should at least say something to each other. They stood quiet and motionless." (108) The two men do not join hands, however, and remain silent. They turn to Marian, a move that deflates the homoerotic tension that has been building alongside the physical activity. This is a significant moment, for the intense activation of body language nearly results in a transgression of normative genre and social positions with regard to both sexual orientation and gender. Peek observes that in the postwar Western,

by limiting the participation of women and their concerns (which, Jane Tompkins argues, is the genesis of the genre), Westerns become a 'safe space' in which to raise questions about masculinity, to perform different kinds of masculinities, and to explore the pleasures and perils of male bonding, with its flagrantly erotic rituals and homosocial dynamics. (210)

The stump-pulling chapter is an excellent example of the type of cultural exploration that Peek sees in the postwar Westerns, and again underlines the degree to which Schafer's Shane presents curious and unusual moments that raise important questions about masculine codes of gender and sexuality through both verbal and nonverbal forms of language.

\section{Conclusion}

As the narrative progresses, Shane moves closer to Joe and away from Marian, paralleling an attending shift in Shane's verbal behavior away from the more open and flexible kind he speaks in the early chapters. This change is symbolically marked by a reconfiguration of Shane's dress from the urban dandy clothes he wears at the start of the novel to the adornment of brown dungarees, a flannel shirt, and a classic Stetson hat, all of which he puts on after agreeing to work with Joe as a farm hand. This shift occurs for a number of reasons. A prominent theme in the narrative is Marian's intense attraction to Shane, with his magnetic, primitive energy wrapped in knightly, genteel manners. Perhaps they both fear 
that engaging in too much open discourse could generate a degree of desire deeply threatening to the family order. This threat also explains why Shane ultimately leaves the valley at the end of the story. Moreover, as the plot evolves, Shane engages in more and more violence. While this shift in Shane's character away from a fairly flexible approach towards certain gender codes to a more normative masculine performance may seem disappointing, it is critical to keep in mind that Shane is not a narrative that seeks to radically equalize all members of society or overturn any number of conventional gender hierarchies. Nor does it offer a paradigm of politically correct ethical, moral, or egalitarian behavior. Rather, my interpretation of Shane resonates with Daniel Worden's more general argument that

cowboy masculinity in modernism exceeds dominant constructions of manhood, even if modernist masculinity is ultimately flattened and streamlined into hegemonic channels, either by narrative structures that force a conventional ending into otherwise unruly texts or hegemonies that eventually contain alternative masculinities within racist, patriarchal logics. (5)

Shane is an apt example of the "cowboy masculinity" that Worden theorizes: an "unruly text" that, in the final analysis, is mainstreamed by the structural forces of a conventional narrative structure, one that upholds hegemonic discourses regarding gender. More than anything, then, the novel - more so than the film raises questions, explores problems, dwells in ambiguity, and presents opportunities for readers to think critically about a range of issues endemic to American history and culture. At certain moments, Shane performs a flexible discourse, one that easily moves between male and female spheres of rhetoric; at others, Shane speaks in ways that are more reserved and narrowly masculine. Silence and nonverbal forms of communication can play socially productive roles, but they can also play unproductive ones, and sometimes the results are mixed, nuanced. Unfortunately, because of the tremendous success of the film adaptation, the novel has been underappreciated. Unfortunately, the novel is often regarded as a socially conservative or "safe" book assigned in middle schools along with texts like John Steinbeck's The Red Pony. There is nothing inherently wrong with reading Shane or The Red Pony in middle school, but relegating it to adolescent reading lists suggests that Shane does not deserve mature respect, perhaps not deserving of continuing scholarly and critical attention. My purpose in this essay has been to show that the novel does, indeed, reward close and critical rereading, offering a critique of Tompkins's view of the relationship between language and gender and its function in the Western, and more broadly, suggesting fresh ways to think about the genre. Shane demonstrates that Western men do not always use language to subjugate women, and that the valuing of language over action does 
not always result in violence or exploitation, that the rejection of language, if it is a rejection at all, signifies the embrace of other forms of communication. In Shane, silence can truly be golden, and actions can truly speak louder than words.

\section{Works Cited}

American Film Institute. “Top 10 Westerns.” AFI’s 10 Top 10. AFI. 2008. 10. Nov. 2011.

Cleary, Michael. "Jack Schaefer: The Evolution of Pessimism.” Jack Schaefer, Shane: The Critical Edition. 319-37.

Costello, Matthew. “'I Didn’t Expect to Find Any Fences Around Here’: Cultural Ambiguity and Containment in Shane." Journal of American Culture 27.3 (2004): 261-70.

Ersiman, Fred. "Growing up with the American West: Fiction of Jack Schaefer.” The Popular Western. Eds. Richard W. Etulain and Michael T. Marsden. Bowling Green: Bowling Green State UP, 1974. 710-6.

Giri, Vijai N. "Nonverbal Communication Theories." Encyclopedia of Communication Theory. Eds. Stephen W. Littlejohn and Karen A. Foss. Vol. 1. Thousand Oaks: SAGE Publications, Inc., 2009. 690-4.

Iseminger, Gordon L. “Corral Posts and Tree Stumps: Symbolism in Jack Schaefer's Shane.” South Dakota Review 41.1-2 (2003): 250-9.

Marsden, Michael T. "The Making of Shane: A Story for All Media." Jack Schaefer, Shane: The Critical Edition. 338-53.

McVeigh, Stephen. The American Western. Edinburgh: Edinburgh UP, 2007.

Mikkelsen, Robert. “The Western Writer: Jack Schaefer's Use of the Western Frontier.” Jack Schaefer, Shane: The Critical Edition. 151-5.

Mitchell, Lee Clark. “'When You Call Me That...': Tall Talk and Male Hegemony in The Virginian.” PMLA 102.1 (1987): 66-77.

Peek, Wendy Chapman. "The Romance of Competence: Rethinking Masculinity in the Western." Journal of Popular Film \& Television 30.4 (2003): 206-19.

Reeser, Todd W. Masculinities in Theory: An Introduction. Chichester, West Sussex: Wiley-Blackwell, 2011.

Schaefer, Jack. Shane: The Critical Edition. Ed. James C. Work. Lincoln: U of Nebraska P, 1984.

Shane. Directed by George Stevens. Perf. Alan Ladd, Jean Arthur, Van Heflin, Brandon De Wilde, and Jack Palance. Paramount, 1953.

Slotkin, Richard. Gunfighter Nation: The Myth of the Frontier in Twentieth-Century America. Norman: Oklahoma UP, 1992.

Tompkins, Jane. West of Everything: The Inner Life of Westerns. Oxford: Oxford UP, 1992.

Worden, Daniel. Masculine Style: The American West and Literary Modernism. New York: Palgrave Macmillan, 2013.

Work, James C. "Settlement Waves and Coordinate Forces in Shane." Western American Literature 14 (1974): 191-200. 